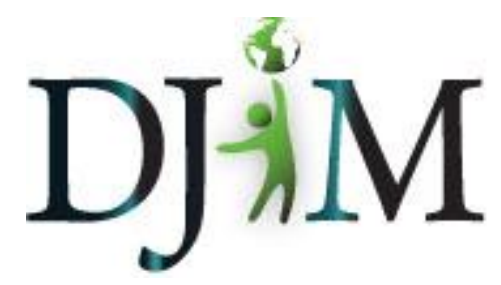

Volume 8 - Spring 2012 djim.management.dal.ca

\title{
An analysis of Four Fish: The Future of the Last Wild Food by Paul Greenberg, 2010, Penguin Publishing.
}

\begin{abstract}
The book report examines Four Fish: The Future of the Last Wild Food by Paul Greenberg, as published by Penguin Publishing in 2010. Greenberg's offering to ocean governance literature is differentiated from comparable works in the depth of historical analysis used to explain the current state of affairs as well as its language used to undertake such a feat. His accessible analysis is divided into four chapters- one for each of cod, salmon, bass, and tuna -where he effectively provides species specific commentary on the science and the prospective good and previously faulty policies undertaken. For anyone interested in ocean governance, public policy, and what winds up on your plate, Greenberg provides a sound introduction to the topic and much food for thought.
\end{abstract}

\begin{abstract}
About the Author(s): Michael Cestnik intends to graduate in 2012 as a Master of Public Administration from the Dalhousie Faculty of Management. He has worked for a variety of public, private, and non-governmental organizations including the Office of the Auditor General of Canada as well as the World Wildlife Fund.
\end{abstract}




\section{An analysis of Four Fish: The Future of the Last Wild Food by Paul Greenberg, 2010, Penguin Publishing.}

Paul Greenberg has written a captivating, well-researched and pragmatic analysis of the current world state of fisheries and fisheries management. He does this analysis of 'the future of the last wild food' with the species of salmon, tuna, bass, and cod by taking turn to address each individually in turn. With each, he examines the relevant history behind the species to explain the benefits, flaws, and problems that each has uniquely encountered or continues to face. The targeted audience of such a work is anyone interested in ocean governance, aquaculture, the environment or food security.

Greenberg is a regular writer for the New York Times and novelist who has written on fish related and other environmental portfolio items; he has also written for The Times of London, GQ, Vogue, Cooking Light, Food and Wine, National Geographic and many other publications. His book is written in simple language to make the scientific concepts and systems accessible to the layperson and provides effective big picture understanding for those who have scientific tunnel vision. It is as much a historical account as a current affairs book addressing an issue of humanity's follies and triumphs with fish.

Greenberg illustrates the failures as well as successes of efforts made to try and combat declining fish stocks - aquaculture, polyculture, marine protected areas, and international treaties. The tone is neutral and narrative for the most part of the book, again illustrating much of the historical significance in 'how we got here'. He takes the time to positively portray the brilliant scientific minds that helped make aquaculture possible through overcoming significant challenges but does not equally criticise those whose decisions have had negative effect. For the most part, he portrays these parties as not knowing any better - himself included. If anything, Greenberg casts himself as a man who loves fishing but only through time and great error realises himself as a part of the problem and as a hypocrite in order to illustrate that it is an individual human flaw that causes the collective problem.

Though these sections stray from statistics and policy, they illuminate the mood and attitudes of him and fellow fishermen as they toil. This proves very useful and serves to illustrate matters such as Hardin's 'tragedy of the commons' and humanity's continuous historical overestimation of stock health. Some elements stray from that of the issues faced into the ways in which Greenberg himself has been a lifelong fisherman and recounts his own personal experiences from fishing as a youth to hunting tuna on the high seas as an adult.

Greenberg is original and useful in a number of policy recommendations. He is perhaps most original in the sphere of aquaculture being addressed in popular literature, in asserting that the fish chosen to be those eaten or 'domesticated' by humanity are not ideal in the complexity of facilitating aquaculture and/or their inefficient rate of turning feed into flesh. This notion is one half policy and one half history; an explanation of why and a suggestion of the courses that may be more efficient in these increasingly dire times for the ocean.

The fourth and final chapter addresses the complex case of tuna and the failure of the International Commission for the Conservation of Atlantic Tunas (ICCAT) in setting catch limits

An analysis of Four Fish: The Future of the Last Wild Food by Paul Greenberg, 2010, Penguin

Publishing. 2 
that 'are not respected and are largely ineffective in controlling overall catch' and furthermore that the current management practices have helped propagate the stock's decline. Greenberg asserts that he believes that tuna by all means is an unmanageable fish and does not advocate a 'silver bullet' in his conclusions. This hinges on the perhaps correct conclusion that humanity will step in to protect an animal from extinction if it sees it more as animal and not as food - as has been the case with whales. Moving tuna off the dinner table simply is not a decision that many parties are interested in undertaking, thus Greenberg has made a compelling and complete, if depressing, conclusion.

Not all of Greenberg's assertions are so complete however. His portrait of the current situation is correct - as humans, we may successfully be able to recreate aquaculture that succeeds at creating fish biomass for food, but he asserts that we could be more successfully re-enabling these ecosystems to have entire eco-zones with stewardship granted to local fishermen to maintain as their livelihood. This is perhaps more difficult in idea than in practice as coastal shelves do not merely end at national 200 nautical mile boundaries, as with the Canadian Grand Banks. With such an example, if Canada were to create a fishing stewardship-zoning scheme, outside Spanish and Portuguese fleets could continue to harvest and jeopardise stock health in international waters. Canada would then have to employ a policy similar to Iceland in enforcing or furthering its exclusive economic area with diplomacy or military vessels to make such a stewardship scheme work; such an item was certainly not addressed in Greenberg's sound, but perhaps incomplete, recommendations. This is understandable given the nature of target audience of the book, and that whatever conclusions are drawn cannot necessarily be applied universally.

In conclusion, Greenberg has provided a remarkably accessible analysis of the history, science, and policy relating to the current state of ocean governance and provides analysis for the future. Considering this significant breadth and target audience, his recommendations are not necessarily globally applicable but provide a positive, attainable alternative to the current state of affairs. It is a must read for anyone wishing to understand the past, present, and future of ocean governance for humanity's four fish. 


\section{SOURCES USED}

Greenberg, P. (2010). Four fish: The future of the last wild food. Penguin Publishing.

Greenberg, P. (2011). Four fish by Paul Greenberg, New York Times best seller and notable book. Retrieved from http://www.fourfish.org/authorbio.html

Icelandic coast guard / English. (2011). Retrieved from http://www.Ihg.is/english

An analysis of Four Fish: The Future of the Last Wild Food by Paul Greenberg, 2010, Penguin 